\title{
DA CULTURA DO CORPO DAS CRIANÇAS: DIFERENÇAS E SIGNIFICADOS PRODUZIDOS NAS AULAS DE EDUCAÇÃO FÍSICA
}

\author{
ABOUT CHILDREN'S BODY CULTURE: DIFFERENCES AND MEANINGS \\ PRODUCED DURING PHYSICAL EDUCATION CLASSES
}

\section{LA CULTURA DEL CUERPO DE LOS NIÑOS: DIFERENCIAS Y SIGNIFICADOS PRODUCIDOS EN LAS CLASES DE EDUCACIÓN FÍSICA}

\author{
Flávia Martinelli Ferreira*, Jocimar Daolio*, Dulce Filgueira de Almeida*
}

Palavras chave:

Criança.

Corpo.

Antropologia.

Educação Física.

Keywords:

Child.

Body.

Anthropology.

Physical Education.

Niño.

Cuerpo.

Antropología.

Educación Física.

\begin{abstract}
Resumo: Este artigo tem como objetivo compreender como as diferenças e os significados são produzidos nas aulas de Educação Física (EF) a partir das dinâmicas culturais infantis, envolvendo os processos de diferenciação que ocorrem no corpo das crianças. Um estudo de cunho etnográfico foi realizado em uma turma de quarto ano de uma escola pública na cidade de Jundiaí/SP, composta por vinte e seis crianças, contribuindo com as discussões desempenhadas neste artigo sobre sua construção cultural do corpo nas aulas de Educação Física, entendendo que as diferenças produzidas e estabelecidas entre as crianças estão em constante transformação e atreladas aos conhecimentos específicos da EF. Por meio deste estudo, concluímos que a mediação pedagógica favorece a construção de novos conhecimentos a partir das diferenças estabelecidas, considerando a construção cultural do corpo das crianças e relativizando as marcas produzidas neste corpo dentro e fora da escola.
\end{abstract}

\begin{abstract}
This paper looks into how children's cultural dynamics during Physical Education classes produce distinctions and meanings concerning differentiation processes related to their bodies. An ethnographic study was undertaken with 26 students of a 4th grade class from a public school in the city of Jundiaí, Brazil. This procedure contributed to this paper's discussions about the development of a body culture in Physical Education classes, since the differences produced and established by children are constantly changing and are related to specific knowledges in the field of Physical Education. We conclude that knew knowledges are built through pedagogical mediation regarding the differences produced by children, considering the cultural construction of children's bodies and relativizing the marks produced in those bodies inside and outside school.
\end{abstract}

Resumen: Este artículo tiene como objetivo comprender cómo las diferencias y los significados son producidos en las clases de Educación Física (EF) a partir de las dinámicas culturales infantiles, incluyendo los procesos de diferenciación que ocurren en el cuerpo de los niños. Un estudio de cuño etnográfico fue realizado en un grupo de cuarto año de una escuela pública en la ciudad de Jundiaí, SP, compuesto por veintiséis niños, contribuyendo a las discusiones desarrolladas en este artículo sobre la construcción cultural del cuerpo en las clases de educación física, entendiendo que las diferencias producidas y establecidas entre los niños están en constante transformación y entrelazadas a los conocimientos específicos de la ef. A través de este estudio, concluimos que la mediación pedagógica favorece la construcción de nuevos conocimientos a partir de las diferencias establecidas, considerando la construcción cultural del cuerpo de los niños y relativizando las marcas producidas en ese cuerpo dentro y fuera de la escuela.
*Universidade de Brasília. Brasília, DF, Brasil.

E-mail: laviamartinelli@uol.com.br dulce.filgueira@gmail.com

*UNICAMP. Campinas, SP, Brasil. E-mail: jocimar@fef.unicamp.br

Recebido em: 04-04-2017 Aprovado em: 30-08-2017

DOI: http://dx.doi.org/10.22456/1982-8918.72415 (c) (i) () Licence 


\section{INTRODUÇÃOO}

Partimos de uma pesquisa que tinha como objetivo central compreender como as diferenças e seus significados são produzidos nas aulas de Educação Física, por crianças do quarto ano do ensino fundamental da Prefeitura de Jundiaí/SP, para debater a construção cultural do corpo das crianças na escola. A diversidade dos espaços e tempos escolares é composta por processos de diferenciação de gênero, classe, idade, tradições culturais, entre outros. Neste sentido, essas diferenciações, que ocorrem também nos processos de ensino e aprendizagem, delineiam o corpo das crianças considerando possíveis distinções produzidas neste processo ativo. Se o corpo como uma construção cultural é discutido no livro Da cultura do corpo, de Daolio (1995), pretendemos neste artigo evidenciar esta dinâmica presente nas aulas de Educação Física a partir do estudo dos processos de diferenciação que ocorrem entre as crianças.

O corpo humano é apresentado, na obra supracitada, ao mesmo tempo como uma construção social e como um dado natural, revelando a tendência de pensá-lo como exclusivamente biológico que vigorava no campo da Educação Física (DAOLIO, 1995). Por meio das contribuições da Antropologia Social, o autor empreendeu discussões acerca de seu objeto de estudo - o corpo - como uma sede de signos sociais, ou seja, como lócus de expressão e produção de culturas em determinadas sociedades. A compreensão do autor, ancorada na perspectiva de Marcel Mauss, expurga o caráter puramente biológico do corpo e passa a considerar o conjunto de significados nele inscritos. A distinção entre a natureza e a cultura do corpo foi apresentada e reforçada ao longo da trajetória das pesquisas em Educação Física, no entanto, consideramos que processos de incorporação inscrevem conteúdos culturais nos indivíduos, compondo o conjunto de suas expressões, ou, dito de outra forma, a cultura é apreendida pelos seres humanos também por meio de seu corpo.

Da mesma forma, compreendemos que tanto as discussões acerca do corpo quanto a infância estiveram confinados, durante muito tempo, a estes mesmos reducionismos, assinalando a necessidade de estudos que forneçam atenção devida à dimensão corporal das crianças. Considerando a produção científica no campo da Sociologia da Infância, é admissível expor que o corpo e a infância são tomados de forma abreviada, sendo pouco estudados como uma unidade biopsicossocial que considera suas diversas facetas (GAITÁN, 2006).

Vale ressaltar, em contrapartida, que os estudos do campo da Sociologia da Infância apresentam lacunas que emanam das descrições sociológicas e antropológicas do corpo e da infância. No caso das pesquisas etnográficas, considerar o ponto de vista das crianças somente a partir de suas falas é também uma forma de negligenciar o conjunto de manifestações e técnicas corporais presentes nas práticas culturais das crianças.

A premissa de considerarmos as crianças como atores sociais envolvidos em processos de produção e reprodução cultural tem permeado discussões no campo pedagógico e sociológico ${ }^{1}$, considerando que estas instâncias não deixaram, em nenhuma medida, de se interessar pelo corpo como um espaço privilegiado de introspecção de práticas educacionais. Os processos de socialização na infância buscam ser compreendidos de forma mais acentuada a partir da dimensão corporal das crianças, sendo esta uma dimensão palpável e que permanece hegemonicamente sob controle e domínio em espaços escolares (BUSS-SIMÃO et al., 2010).

1 Exemplos de produções científicas a respeito do tema: Montandon (2001), Delgado e Müller (2005), Buss-Simão et al. (2015). 
O empenho, neste ínterim, é apresentar um estudo composto dos significados produzidos pelas crianças em relação à construção cultural de seus corpos na infância. As questões que serão apresentadas a seguir são fruto de um estudo de cunho etnográfico no transcurso de dois bimestres letivos junto a uma turma de quarto ano do ensino fundamental da Prefeitura de Jundiaí/SP durante as aulas de Educação Física. Os episódios apresentados neste artigo fazem alusão às questões vivenciadas pelas crianças relacionando seus diferentes pesos corporais e as atividades desenvolvidas em aula, ou, dito de outro modo, acenam para as diferenças estabelecidas entre os gordinhos em relação ao restante da turma.

Com este trabalho, buscamos destacar como as diferenças e seus significados são produzidos nas culturas infantis construídas neste espaço e tempo. Estas explicações científicas, como reitera Lévi-Strauss (1989), não são constituídas de uma redução do complexo ao simples. De modo contrário, são compostas pela substituição de uma complexidade menos inteligível por outra mais inteligível. Situadas em um contexto particular, tornar as complexidades observadas inteligíveis não significa generalizar de forma descuidada a realidade apreendida. Significa - e este trabalho é constituído por esta tentativa - vislumbrar algumas possibilidades considerando a importância da construção cultural do corpo das crianças para as aulas de Educação Física.

\section{DELINEAMENTO METODOLÓGICO}

Com o empenho de compreender como as diferenças e seus significados são produzidos nas dinâmicas culturais infantis construídas no espaço e tempo das aulas de Educação Física, tomamos caminhos para a elaboração de um estudo de cunho etnográfico pautado nos estudos de Geertz (2011; 2006; 2001). Desta maneira, o intuito é que as descrições e suas interpretações sejam capazes de assinalar alguns significados envolvidos nas ações e representações das crianças. Para formular princípios e sugerir diferentes explicações a respeito dessa dinâmica, a organização da vida social das crianças foi decifrada em símbolos e representações, tracejando nesse sentido uma "descrição densa" como proposta pelo autor.

A Prefeitura de Jundiaí serviu de cenário para a pesquisa de campo ${ }^{3}$ desenvolvida ao longo de dois bimestres letivos. Inicialmente foram estabelecidos alguns critérios de seleção das escolas da rede municipal, como o acesso à escola, turmas de quarto ano do ensino fundamental e as aulas ministradas por professores efetivos da rede. A turma em questão era formada por vinte e seis crianças, oito meninos e dezoito meninas, entre nove e oito anos de idade. Os episódios analisados no estudo de cunho etnográfico são um recorte não cronológico das observações realizadas durante o trabalho de campo entre os meses de agosto e dezembro de 2014. Os nomes usados ao longo do texto foram escolhidos nos últimos dias da pesquisa pelas próprias crianças. As crianças que estiveram ausentes naqueles dias tiveram os nomes fictícios escolhidos por outros colegas.

Com a prática da etnografia foi possível estabelecer relações entre os atores sociais e suas ações, selecionar os informantes mais adequados, transcrever os textos e manter um diário de campo durante as observações, como proposto por Geertz (2011). O autor explica

\footnotetext{
2 A etnografia é um estudo elaborado com o intuito de compreender diferentes significados, estabelecendo supostas hierarquias. Estes significados são produzidos, percebidos e interpretados, caracterizando o que Geertz (2011) classifica como uma "descrição densa", ou seja uma interpretação das respostas fornecidas ao longo do estudo pelos nossos informantes. Portanto, além de elaborarmos uma descrição minuciosa, é necessário também compreender os significados envolvidos nas ações dos atores sociais estudados.

3 Esta pesquisa foi aprovada pelo Comitê de Ética em Pesquisas da UNICAMP - no CAAE: 32907814.1.0000.5404.
} 
também que os estudos são iniciados com interpretações sobre o que pretendem os "nativos" - ou o que os pesquisadores acham que eles pretendem. Destarte, o trabalho desempenhado por uma etnografia é o de proporcionar narrativas capazes de redirecionar nossa atenção e de fornecer novas explicações a respeito dos temas e atores sociais observados (GEERTZ, 2001). Assim, é possível pensarmos na diversidade cultural a partir de percepções e compreensões que são formadas a partir das observações das dinâmicas culturais infantis e da construção do corpo nas aulas de Educação Física. As culturas infantis foram tomadas como um conjunto de textos que tentaremos ler e compreender para ordenar os temas em uma estrutura que organiza a vida social das crianças. Essa possibilidade de análise, para Geertz (2011), tem um papel interpretativo, não o intuito de professar fórmulas redutivas.

Corroboramos Cardoso de Oliveira (2000) entendendo que a maior dificuldade, no caso, está nas diferenças entre os "idiomas culturais". Para compreender a cultura do outro, é necessário transformá-lo em um interlocutor. Isto porque, para o autor, elaborar perguntas em busca de respostas rápidas favorece um campo ilusório de interação entre os sujeitos. É possível então que, a partir de categorias e conceitos básicos escolhidos pelo pesquisador, este traduza e interprete o que ouviu e escreveu durante a pesquisa de campo. Do mesmo modo, Corsaro (1997, p. 95) compreende que a "Cultura de pares é pública, coletiva e performativa, isto é: um conjunto estável de atividades ou rotinas, artefatos, valores e preocupações que crianças produzem e compartilham em interação com pares". Dizer que as culturas infantis são dinâmicas indica que estas não estão fixas no entorno das crianças, mas que são passíveis de mudanças e de novas descobertas. Por outro lado, a observação de fenômenos culturais não deve tomar a cultura apenas como uma variável, mas sim empreender uma análise sobre a dinâmica da cultura, ou seja, considerar esta dinâmica como um processo permanente de reconstrução e organização de ações e representações (DURHAM, 2004, p. 231).

A partir deste delineamento metodológico, a pesquisa buscou compreender as crianças como produtoras e produtos da cultura. As dinâmicas culturais infantis, neste sentido, devem envolver a dimensão corporal como fundamental na educação das crianças, já que é sua materialidade palpável que incorpora os processos educacionais que permeiam as aulas de Educação Física (BUSS-SIMÃO et al., 2010). Sendo assim, apresentaremos a seguir formas de dar sentido e significado às ações das crianças, as quais são estabelecidas e anunciadas como diferenças de forma dinâmica nestes contextos.

\section{A CONSTRUÇÃO CULTURAL DO CORPO DAS CRIANÇAS: CONSIDERAÇÕES SOBRE "SER GORDINHO"}

Apresentando uma perspectiva sociológica, Le Breton (2006) explicita que a condição corporal é um fenômeno social e cultural. Com isso, toda ação que é responsável por tecer a trama da vida cotidiana envolve determinadas mediações em relação à corporeidade. Essa mediação permite aos seres humanos - e, portanto, às crianças - de modo dinâmico, ver, compreender, negar, tocar e repelir, intervindo com significações próprias sobre o corpo no mundo que os cerca. O corpo, neste âmbito, é uma forma simbólica, um universo de significados em movimento e constantemente reencenados.

Uma pesquisa de caráter etnográfico foi desenvolvida com 0 intuito de observar como as crianças criavam e encenavam estas diferenças corporais em espaços como a 
escola ou suas próprias casas (JAMES; JENK; PROUT, 2000). Cinco aspectos foram listados como significativos em relação ao corpo das crianças ao longo deste estudo: as estaturas, formas, aparências, o desempenho e as diferenças de gênero entre os sexos. Concluiu-se, neste sentido, que cada um desses aspectos é uma fonte passível de transformação nas interações entre as crianças e no decorrer da construção de suas identidades. Para superar reducionismos, os autores propõem o entendimento de processos de corporificação como um espaço de criação e reinvenção das crianças, isto é, um lugar no qual ativamente as crianças assimilam, reproduzem e produzem novas formas de entendimento sobre o corpo e o mundo social.

De maneira similar, nesta seção assumiremos episódios extraídos das observações realizadas em um estudo de cunho etnográfico, que serão apresentados e agrupados para serem analisados, referindo-se aos reiterados casos em que as crianças alçavam questões relacionadas às suas diferenças e às desigualdades experimentadas com o corpo nas aulas de Educação Física. Os episódios aqui apresentados referem-se, em especial, aos diferentes pesos corporais das crianças e de seus colegas, sempre conectados às propostas de atividades desenvolvidas nas aulas e aos temas referidos do período de observação. Estes episódios, relacionando as diferenças estabelecidas entre os gordinhos nas aulas de Educação Física, serão, portanto, melhor desenvolvidos e discutidos adiante.

Entendidas como consequência de atos da linguagem, as diferenças são produzidas por meio de relações culturais, e a estas diferenças são atribuídos significados que emergem da relação das crianças com os adultos e das próprias crianças entre si. As diferenças têm seu surgimento e constituição em contextos sociais e são significadas por intermédio de um ser humano com outro. São resultados de atos de criação linguística, produzidas ativamente em um contexto de relações culturais e sociais aos quais estamos constantemente sujeitos (SILVA, 2009).

Vivências experimentadas pelas crianças nas tentativas de realizar estrelas, paradas de cabeça ou outros movimentos que eles consideram mais difíceis referentes à ginástica ${ }^{4}$ sempre foram discutidas ao final de cada aula de Educação Física. Com espaço para discutir estes feitos, alcançados durante as aulas, as crianças questionavam por que os gordinhos tinham mais dificuldades, descobriam com quais partes do corpo deveriam fazer mais força e estavam atentos às dicas fornecidas pelo professor para facilitar o processo. Os debates, que pareciam longos demais para as crianças que queriam experimentar mais vezes os movimentos durante as aulas, foram fundamentais para a construção de saberes sobre o fazer corporal nas aulas de ginástica.

Notando que os colegas mais pesados demonstravam certas dificuldades na execução da parada de cabeça, Alice insinuou a eles e ao professor que as crianças pesadas não conseguiriam realizar os movimentos. Uma das crianças mencionadas por Alice, Lucas, também era destacado por outras crianças e considerado gordo diante dos comentários de grande parte da sala. Em seu papel de mediar questões e comentários referentes à aula, o professor contrapôs o comentário explicando que o peso corporal das crianças deve ser considerado e tem um papel importante, mas não impede a execução dos movimentos, apenas facilita ou dificulta o processo. Para complementar, também apontou outros fatores que devem ser considerados, como a força e o jeito para conseguir fazer, por exemplo, a parada de 
cabeça, atividade proposta no início das aulas que tematizavam a ginástica. Impulsionado pelos comentários realizados pelo professor e considerando seus êxitos durante as atividades propostas em algumas aulas de ginástica (como a parada de cabeça, a vela, o avião e diferentes tipos de saltos), Lucas comentou em seguida: Eu sou gordinho e consegui, ué.

As discussões sobre o peso corporal eram frequentes durante as aulas de ginástica porque o peso parecia ser - para as crianças - determinante para seu sucesso ou fracasso na experimentação dos movimentos propostos. Com o desenvolver das aulas, os elementos da ginástica foram agrupados e explorados de maneira mais específica em aulas de ginástica acrobática. Ao final deste processo, as aulas de Educação Física deveriam garantir às crianças conhecimentos e experimentações de atividades que, segundo o professor, compõem a ginástica acrobática, como as pirâmides humanas, as paradas de cabeça e paradas de mão, além de diferentes formas de executar saltos.

Os lugares ocupados nas atividades de ginástica acrobática também eram definidos de acordo com esta categoria do peso corporal. Para facilitar a construção das pirâmides acrobáticas, por exemplo, o professor iniciou a apresentação desta atividade com a sugestão de que as crianças mais fortes e pesadas ficassem nas bases das pirâmides. Não por acaso, os papéis inicialmente sugeridos pelo professor se consolidaram ao longo das aulas, e era incomum observar crianças que circulavam entre estes papéis: as bases, que ficavam embaixo das pirâmides, os volantes, que subiam no topo das pirâmides, e os intermediários, que tanto eram encontrados entre as bases e os volantes, como em espaços anexos às pirâmides, auxiliando outros colegas durante sua experimentação.

Embora os papéis previamente definidos agradassem a maior parte das crianças, Rodrigo questionava durante as aulas que as bases eram formadas apenas de crianças mais pesadas: Só os pesados querem carregar e os mais leves não podem! Durante as experimentações, tentou inúmeras vezes propor aos colegas a substituição do papel (de intermediário) desempenhado por ele. Conversando com os colegas, Rodrigo conseguiu apenas mudar de grupo, onde desta vez ele era considerado mais pesado que os demais e, portanto, ocupava a base da pirâmide acrobática; no entanto, a lógica dos lugares ocupados nas atividades não foi alterada.

Outros episódios observados demonstram que Lucas, Ivan e Matheus tinham uma relação tensa, vivenciada de diferentes formas ao longo das aulas. Estavam constantemente se provocando e brigando. Em conjunto, Lucas e Ivan provocavam Matheus. Diziam que 0 colega era gordo e, quando este reclamava para o professor, seus colegas argumentavam que também eram gordos, como uma tentativa de minimizar os insultos proferidos, mas retificavam o comentário afirmando que mesmo sendo gordinhos conseguiam realizar as atividades, ao contrário de Matheus.

Com palavras de incentivo e provocações, a diferença entre as três crianças não era física: todos eles se consideravam gordinhos. Porém, a condição vivenciada por Lucas e Ivan, como gordinhos que conseguem realizar as atividades propostas, conferia aos dois, por consequência, certo poder em relação a Matheus, que demonstrava mais dificuldade na execução das tarefas. Ser bem-sucedido nas aulas de Educação Física e conseguir realizar as atividades propostas era o suficiente para que saíssem desta condição apresentada como negativa dos gordinhos que não eram capazes, estabelecida por seu peso corporal em relação a outros colegas, e desempenhassem outro papel, agora como gordinhos que sabem fazer. 
Sempre que os conflitos aconteciam, Lucas e Ivan eram afastados e o professor conversava em particular com Matheus. Em uma das conversas, o professor questionou: Eles são magros? Não, então não liga pra eles. No entanto, o argumento do professor, que parecia igualar as condições entre os meninos, não era suficiente, neste caso, porque desconsiderava que, mesmo gordinhos e supostamente iguais, a relação social estabelecida entre Lucas, Ivan e Matheus sustentava suas diferenças e gerava conflitos durante a aula. De acordo com Silva (2009), as diferenças estabelecidas entre seres humanos são frutos destas relações sociais, como dito anteriormente. Se é possível encontrarmos diferenciações, estas também estão permeadas de relações de poder, que constituem processos de estigmatização destas diferenças. As marcas desta presença são produzidas em nossa sociedade, segundo o autor, nos inúmeros processos de inclusão e exclusão, nos processos de classificação ou ainda em processos de normalização. A marcação da diferença gera inclusões e exclusões diferenciando o que fica dentro ou fora e hierarquizando grupos, atribuindo diferentes valores aos membros de determinadas sociedades. Para o autor, sempre prevalecem as formas de classificar estruturas em oposições binárias ou classes polarizadas. Destacamos, portanto, que a escola sempre teve repulsa ao diferente e à desordem. No entanto, as relações de poder e de diferenciação entre as crianças são produzidas tanto fora da escola quanto no decorrer das aulas. Embora o respeito à diversidade seja uma bandeira constante de todas as instituições escolares, isto não nos impede de considerar essas diferenças como produtos também construídos dentro das próprias instituições (FERREIRA; DAOLIO, 2014).

Considerar as diferenciações como produções sociais pressupõe argumentar a favor de estratégias pedagógicas e curriculares para abordar essas diferenças, discutindo suas produções e os mecanismos que estão envolvidos em sua criação e fixação. Para tanto, é necessário adotar estratégias que expliquem os processos de produção das diferenciações, não admitindo explicações superficiais a respeito do tema (SILVA, 2009).

As discussões sobre o peso corporal das crianças não apareceram exclusivamente relacionadas ao tema da ginástica. Essas discussões apareceram também ao longo das vivências e experimentações realizadas nas aulas que tematizavam a luta. As crianças sugerem que os mais pesados podem esmagar os colegas, mas agora com outros significados, o peso corporal ganha particularidades que dão contornos favoráveis ao lutador mais pesado. Nossa, vai quebrar fácil a Marta, comentou um dos meninos, enquanto observava a aluna Marta lutando com Matheus, uma das crianças gordinhas que protagonizaram as aulas de ginástica retratadas anteriormente. Antes do início das atividades, o professor comentou com pesquisadora que as duplas escolhidas para vivenciar as atividades durante aquela aula seriam escolhas propositais, como um recurso pedagógico que despertasse comentários por parte das crianças, para que fosse possível discutir sobre estas diferenças ao final da aula. A atividade escolhida pelo professor para potencializar essas discussões e evidenciar algumas diferenças foi proposta da seguinte maneira: em duplas, as crianças precisavam fugir dos pisões de seus colegas. Segundo o professor, a vivência permitia aos alunos experimentar de maneira lúdica a movimentação necessária durante as lutas de boxe, que demandam agilidade e atenção dos participantes. 0 objetivo era acertar três pisões no pé do colega para vencer e, depois deste número, novas duplas eram formadas pelo professor.

A primeira disputa aconteceu entre Matheus e Marta. As crianças que observavam os colegas se preparando para realizar a atividade tinham certeza que a colega seria esmagada 
por Matheus. Como pensado pelo professor, a atividade, que demandava agilidade, foi vencida por Marta, que era mais leve e um tanto mais ágil que Matheus, fugindo de todas suas tentativas de pisadas. Antes de iniciar a próxima luta, o professor comentou com a turma: Eu avisei, não importa o tamanho e o peso de vocês pra essa atividade. 0 caráter vivencial da atividade, neste sentido, é indispensável para a construção de conhecimentos relacionados ao corpo e suas peculiaridades durante as aulas de Educação Física. Para Betti (1994, p.42, grifo do autor), o saber corporal "[...] não pode ser alcançado pelo puro pensamento; é um saber orgânico, só possível com as atividades corporais, não é um saber que se esgota num discurso sobre o corpo/movimento". Neste sentido, o autor considera que, além de um "fazer corporal", estão envolvidos saberes sobre esse movimentar-se; por outro lado, isso não significa retirar uma ação pedagógica das aulas de Educação Física e transformá-la em um discurso sobre 0 movimento (BETTI, 2007).

As experiências nas aulas de Educação Física são, deste modo, uma forma de nos comunicarmos com o mundo que nos constitui e de contribuir com a construção cultural da qual fazemos parte (BRACHT, 1996). São formas de linguagem que habitam o mundo simbólico e devem ser compreendidas por seu duplo caráter, ser um saber fazer e um saber sobre este fazer. O recurso pedagógico anunciado pelo professor, com isso, é uma importante ferramenta para suscitar discussões sobre as diferenças percebidas durante essas experimentações nas aulas de Educação Física, contemplando essa duplicidade.

Essas questões sobre a influência do peso corporal das crianças apareceram, de igual modo, em um dos diagnósticos sobre o tema, realizado pelo professor nas primeiras aulas do quarto bimestre, antes do início das vivências e das experimentações. As questões sobre as diferenças entre os meninos e as meninas, sobre a importância de ser forte no decorrer das aulas de luta e questões relacionadas ao peso corporal estão representadas e reunidas em um dos textos elaborados por uma criança. Estas sondagens 5 foram propostas pelo professor com a intenção de saber o que as crianças já conheciam sobre a luta.

Os entendimentos demonstrados pelas crianças sobre seu peso corporal eram frequentes nas aulas de Educação Física, tanto no decorrer das aulas quanto nos registros escritos elaborados pelas crianças. Como destacam Tomás e Soares (2004, p. 359): "[...] os processos de relações, negociações, confrontos que se desenvolvem entre elas e com os adultos, são bem reveladores da referida competência e da legitimidade da sua ação nas esferas privada e pública dos seus quotidianos". Destarte, além de constatações sobre ser magro ou forte, por exemplo, eram construídas em seu entorno diferenças socioculturais estabelecidas nas relações entre os pares. Pretendemos, neste sentido, evidenciar que as aparentes constatações que emanam das aulas de Educação Física, como ser gordinho demais para determinada atividade ou ser favorecido em outra atividade pelo seu peso corporal, não são questões relacionadas somente a um corpo biológico das crianças. Essas questões possuem também um caráter sociocultural interligado à construção deste corpo, que é produzido e reproduzido pelas crianças na relação com seus próprios pares. Apresentados os episódios, serão desenvolvidas a seguir considerações sobre a produção de diferenças relacionadas à construção cultural dos corpos das crianças nas aulas de Educação Física.

5 Nesta aula, o professor pediu que as crianças elaborassem um texto sobre a luta. Estas sondagens - antes do início das vivências sobre o tema - foram elaboradas pelas 21 crianças presentes. Os textos foram agrupados por temas que se repetiam ao longo de suas primeiras análises. Deste modo, está exemplificada neste trabalho somente uma das sondagens que representa o agrupamento temático dos textos que se referem às diferenças de peso corporal entre as crianças. 


\section{CONSIDERAÇÕES FINAIS: RELATIVIZANDO OS CORPOS EM QUESTÃO}

No decorrer das discussões desenvolvidas neste artigo, pretendemos fornecer elementos que revelam a necessidade de considerarmos as crianças como atores sociais competentes e envolvidos em sua própria construção cultural do corpo. Para tanto, partimos das ideias divulgadas por Daolio (1995), sobre o delineamento de uma construção cultural do corpo, e almejamos contribuir apresentando uma possibilidade a partir das dinâmicas culturais infantis estudadas.

Embora a ruptura entre a natureza e cultura relacionadas ao corpo tenha circunscrito a trajetória das pesquisas em Educação Física, compreendemos que estas instâncias nunca deixaram de ocupar-se do corpo, uma vez que ele é, certamente, um destino privilegiado de parte considerável das práticas educacionais, ainda que, nos discursos educacionais, o argumento predominante tenha como objetivo progredir na direção de uma educação intelectual, buscando a apreensão dos conteúdos já sistematizados destes conhecimentos (BUSS-SIMÃO, et al. 2010).

Se hoje é possível tecer diversas críticas e se posicionar frente a metodologias tradicionais de pesquisa sobre crianças, ainda é possível avançar e garantir o reconhecimento da cientificidade do protagonismo infantil, em busca de uma pesquisa que compreenda as crianças (SARMENTO; PINTO, 1997). Novas metodologias científicas podem ajudar o pesquisador a evitar que seu olhar seja projetado sobre elas, coletando das próprias crianças e de suas ações apenas aquilo que é consequência das representações e ideias do pesquisador.

Com a possibilidade de nos depararmos com as diferenciações produzidas e reproduzidas pelas crianças, entendemos que estas também estão ligadas às relações sociais que são formadas e estabelecidas entre seus pares. Esta marcação da diferença gera inclusões e exclusões capazes de distinguir o que fica dentro ou fora; do mesmo modo, as classificações hierarquizam o grupo e atribuem diferentes valores aos seus membros. Considerando as observações relatadas, elaboramos algumas reflexões acerca do tema que pretendem contribuir com a prática pedagógica das aulas de Educação Física.

Defendemos que a mediação pedagógica deve acontecer com o intuito de facilitar vivências que descaracterizem "lugares" ocupados pelas crianças durante as aulas, além de oportunizar discussões capazes de relativizar as marcas produzidas no corpo dentro e fora da escola. De tal modo, não basta que as crianças ocupem lugares predeterminados nas aulas, é necessário saber por que ocupam estes lugares e incentivar novas possibilidades. Neste sentido, a associação entre o peso das crianças e a força, por exemplo, está assentada em uma concepção do senso comum que poderia ser relativizada e debatida com as crianças por iniciativa do professor.

Os saberes cotidianos das crianças, portanto, não devem estar subordinados ao conhecimento sistematizado da Educação Física, mas devem transformar este encontro em uma relação cíclica: os saberes das crianças devem ser acessados pelo professor, em um trânsito do senso comum ao conhecimento científico, e este deverá propor novos conhecimentos às crianças. Quando as possibilidades de um conteúdo estão esgotadas, por exemplo, o ciclo se renova para a mobilização de novos saberes presentes no senso comum, que serão novamente confrontados com os temas da cultura corporal de movimento pelo professor (RODRIGUES JÚNIOR, 2008). 
Ainda considerando a mediação do professor, o encontro e o confronto dos saberes dispostos nas culturas do adulto e nas culturas infantis podem auxiliar a construção de conhecimentos sistematizados e específicos sobre a aula de Educação Física. Por meio de comparações que não buscam a igualdade, mas que constroem novos conhecimentos a partir da diferença, o professor pode propor situações que estimulem as crianças a divulgar seus entendimentos e, neste sentido, um novo conhecimento seria elaborado sobre a constituição cultural do corpo partindo dos conhecimentos próprios das culturas infantis.

\section{REFERÊNCIAS}

BETTI, Mauro. O que a semiótica inspira ao ensino da educação física. Discorpo, n. 3, p.25-45, out. 1994.

BETTI, Mauro. Educação física e cultura corporal de movimento: uma perspectiva fenomenológica e semiótica. Revista da Educação Física/UEM, v.18, n.2, p.207-217, 2 sem. 2007.

BRACHT, Valter. Educação física no $1^{\circ}$ grau: conhecimento e especificidade. Revista Paulista de Educação Física, supl. 2, p.23-28, 1996.

BUSS-SIMÃO, Márcia; MEDEIROS, Francisco E.; SILVA, Ana Márcia. M.; FILHO, João J. Corpo e infância: natureza e cultura em confronto. Educar em Revista, v. 26, n. 3, p.151-168, dez. 2010.

BUSS-SIMÃO, Márcia; ROCHA, Eloisa A. C.; GONÇALVES. Fernanda. Percursos e tendências da produção científica sobre crianças de 0 a 3 anos na Anped. Revista Brasileira de Estudos Pedagógicos, v. 96, n. 242, p.96-111, jan./abr. 2015.

CARDOSO DE OLIVEIRA, Roberto. 0 trabalho do antropólogo. 2. ed. São Paulo: UNESP, 2000.

CORSARO, William. The sociology of childhood. Thousand Oaks, California: Pine Forge, 1997.

DAOLIO, Jocimar. Da cultura do corpo. 15. ed. Campinas, SP: Papirus, 1995.

DELGADO, Ana C. C.; MÜLLER, Fernanda. Apresentação. Educação \& Sociedade, v. 26, n.91, p.351-360, 2005.

DURHAM, Eunice R. A dinâmica da cultura: ensaios de antropologia. São Paulo: Cosac Naify, 2004.

FERREIRA, Flávia; DAOLIO, Jocimar. Educação física escolar e inclusão: alguns desencontros. Revista Kinesis, v. 2, p.52-68, jul. /dez. 2014.

GAITÁN, Lourdes. Sociología de la infancia: análisis e intervención social. Madrid: Sintesis, 2006.

GEERTZ, Clifford. A interpretação das culturas. Rio de Janeiro: LTC, 2011. 
GEERTZ, Clifford. O saber local: novos ensaios em antropologia interpretativa. 8. ed. Petrópolis, RJ: Vozes, 2006.

GEERTZ, Clifford. Nova luz sobre a antropologia. Rio de Janeiro: Jorge Zahar, 2001.

JAMES, Allison; JENKS, Chris; PROUT, Alan. O corpo e a infância. In: KOHAN, W. O.; KENNEDY, D. Filosofia e infância: possibilidades de um encontro. 2. ed. Petrópolis, RJ: Vozes, 2000. p.207-238.

LE BRETON, David. A sociologia do corpo. Petrópolis, RJ: Vozes, 2006.

LÉVI-STRAUSS, Claude. O pensamento selvagem. Campinas, SP: Papirus, 1989.

MONTANDON, Cléopâtre. Sociologia da infância: balanço dos trabalhos em língua inglesa.

Cadernos de Pesquisa, n. 112, p.33-60, mar. 2001.

RODRIGUES JUNIOR, José Carlos. Os saberes cotidianos de alunos nas aulas de educação física: implicações para a prática pedagógica. 2008. 156f. Dissertação (Mestrado em Educação Física) - Faculdade de Educação Física, Universidade Estadual de Campinas, Campinas, SP, 2008.

SARMENTO, Manuel J.; PINTO, Manuel. As crianças e a infância: definindo conceitos, delimitando o campo. SARMENTO, Manuel J.; PINTO, Manuel. In: As crianças: contextos e identidades. Braga: Bezerra, 1997. p.9-30.

SILVA, Tomaz T. A produção social da identidade e da diferença. In: SILVA, Tomaz T. (Org.). Identidade e diferença: a perspectiva dos estudos culturais. 9. ed. Petrópolis, RJ: Vozes, 2009. p. 7-69.

TOMÁS, Catarina A.; SOARES, Natália F. Infância, protagonismo e cidadania: contributos para uma análise sociológica da cidadania da infância. Fórum sociológico, n. 11/12, p.349-361, 2004. 


\section{Apoio:}

Capes, com a concessão de bolsa de mestrado de março de 2014 a março de 2015. 